Article

\title{
Bioaccumulation of Cadmium Affects Development, Mating Behavior, and Fecundity in the Asian Corn Borer, Ostrinia furnacalis
}

\author{
Mei Luo ${ }^{1,2}{ }^{,}$Hong-Mei Cao ${ }^{3}$, Ying-Ying Fan ${ }^{4}$, Xiao-Cao Zhou ${ }^{1}$, Jun-Xian Chen ${ }^{1}$, Henry Chung ${ }^{2}$ \\ and Hong-Yi Wei ${ }^{1, *}$ \\ 1 College of Agronomy, Jiangxi Agricultural University, Nanchang 330045, \\ China; meiluo0522@126.com (M.L.); zxc_422@139.com (X.-C.Z.); cjx116799@163.com (J.-X.C.) \\ 2 Department of Entomology, Michigan State University, East Lansing, MI 48864, USA; hwchung@msu.edu \\ 3 Jiangxi Sericulture and Tea Research Institute, Nanchang 330202, China; chm2017@163.com \\ 4 Geological Survey of Jiangxi Province, Nanchang 330030, China; fy6445952@163.com \\ * Correspondence: hywei@jxau.edu.cn
}

Received: 24 November 2019; Accepted: 18 December 2019; Published: 20 December 2019

\begin{abstract}
Heavy metal pollution is becoming an increasingly serious problem in agricultural ecosystems. Heavy metals such as cadmium (Cd) accumulate in the food chain and may lead to detrimental effects on the physiological functions of living organisms, including herbivorous insects. One such example is the Asian Corn Borer, Ostrinia furnacalis (Lepidoptera: Pyralidae). However, how $\mathrm{Cd}$ can affect the development and reproduction of $O$. furnacalis is largely unknown. In this study, we exposed larvae of $O$. furnacalis to a diet containing $\mathrm{Cd}$ and investigated the effects of $\mathrm{Cd}$ on the development, mating behavior, and fecundity of the insect. We showed that $\mathrm{Cd}$ accumulates in the larvae and inhibits development by extending larval and pupal duration and decreasing the survival rate. The excretion of $\mathrm{Cd}$ through multiple routes during the larval and pupal stages resulted in low levels of residual $\mathrm{Cd}$ in the adult insects, which were not fed with $\mathrm{Cd}$. However, the mating behavior and fecundity of these insects were significantly affected, compared to control insects. This suggests that the bioaccumulation of heavy metals such as $\mathrm{Cd}$ has long lasting and detrimental effects on O. furnacalis over the entire life cycle, affecting fecundity, even when specimens are only exposed at an early life stage.
\end{abstract}

Keywords: Asian Corn Borer; heavy metal; cadmium; development; mating; fecundity

\section{Introduction}

Heavy metal (HM) pollution in the environment results from natural phenomena, such as volcanic eruptions, and anthropogenic activities, such as fossil fuel burning, mining, industrial waste transpiration, and chemical fertilizer applications [1,2]. HMs accumulate in the water supply and soil, which are then transferred into plants, insects, animals, and humans via the food chain [3-5]. These HMs persist in organisms for a long time because they are not easily excreted by the organism. This eventually leads to high levels of HMs in the food chain [6-8].

HMs are toxic, even at low concentrations. An example of this is the HM cadmium (Cd) [9]. In recent years, $\mathrm{Cd}$ pollution has become increasingly worse, with numerous studies reporting increasing Cd pollution in water [10] and agricultural soil [11,12]. One serious consequence of Cd pollution is the accumulation of $\mathrm{Cd}$ in rice $[13,14]$, a major food source for a large proportion of the world's population [15]. The ingestion of Cd-contaminated rice can lead to cadmium poisoning and serious diseases, such as the "Itai-itai disease", which causes bone softening and kidney failure in 
humans [16]. This suggests that $\mathrm{Cd}$ pollution has become a huge problem which does not just affect the environment, but also threatens food safety and human health.

In agricultural systems, plants persistently accumulate $\mathrm{Cd}$ from Cd-polluted soil and transfer $\mathrm{Cd}$ to higher trophic levels through the food chain [17]. Higher tropic-level consumers of crops, such as herbivorous insects, ingest $\mathrm{Cd}$ from their host plants and accumulate $\mathrm{Cd}[4,18]$. For example, a continuous intake of $\mathrm{Cd}$ from plants leads to a high accumulation of $\mathrm{Cd}$ in the entire life cycle of hemimetabolous insects, such as the Chinese rice grasshopper, Oxya chinensis (Orthoptera: Acridoidea) [19]. In the large milkweed bug, Oncopeltus fasciatus (Heteroptera: Lygaeidae), continuous $\mathrm{Cd}$ exposure throughout the entire life cycle led to developmental defects and decreased reproduction [20]. Studies have also shown that $\mathrm{Cd}$ exposure has a negative effect on the growth and reproduction of holometabolous insects [21-23].

These studies mainly focused on the effects of continuous $\mathrm{Cd}$ exposure throughout the entire life cycle of these insects. However, in the field, insects such as Lepidopteran moths only feed on their host plants during the larval stage and do not feed again on the host plant during other life stages $[24,25]$. In addition, many migratory insects may only exhibit $C d$ intake during one life stage because of changes in their habitat [26]. Therefore, it is not known whether the accumulation of Cd during early life stages affects the development and reproduction of these insects throughout their entire life cycles. Understanding how $\mathrm{Cd}$ accumulates and the long-lasting effects of $\mathrm{Cd}$, even when it has exited the organism, is of great importance as it underscores the seriousness of $\mathrm{Cd}$ pollution.

The Asian Corn Borer, Ostrinia furnacalis (Lepidoptera: Pyralidae), is one of the most destructive pests of corn in Asia, Australia, and the Solomon Islands [27,28]. With Cd pollution becoming a serious environmental problem in agro-ecosystems, including corn fields, $O$. furnacalis is constantly exposed to high levels of $C d$ in the environment $[29,30]$. However, there is little research regarding the effect of the accumulation of $\mathrm{Cd}$ on the development and reproduction of $O$. furnacalis. As a holometabolous herbivore, $\mathrm{O}$. furnacalis only ingests $\mathrm{Cd}$ by feeding on its host plants during the larval life stage. The effects of accumulation at an early life stage on adult traits, such as mating behavior and fecundity, are largely unknown. As the sex pheromone system has been well-studied [31] and is sensitive to external stimuli [32], O. furnacalis can also be used as a suitable insect model to study the effects of Cd exposure at an early life stage on the mating behavior and fecundity in an adult life stage.

We exposed O. furnacalis to $\mathrm{Cd}$ at the larval stage and measured the accumulation and excretion of $\mathrm{Cd}$ throughout its entire life cycle. We also investigated the effects of the bioaccumulation of $\mathrm{Cd}$ on the development, mating behavior, and fecundity of $O$. furnacalis throughout the entire life cycle. In this study, we were interested in how O. furnacalis responds to Cd stress, and we specifically focused on the effects of $\mathrm{Cd}$ accumulation on mating behavior and fecundity in the adult stage of $O$. furnacalis, during which there is no $\mathrm{Cd}$ intake. Our previous research has studied the effects of $\mathrm{Cd}$ on the mating responses of female adults and showed that $\mathrm{Cd}$ stress can have detrimental effects on adult females, but we did not perform the experiment in males [33]. Therefore, in this study, we further measured the effects of $\mathrm{Cd}$ on mating responses of male adults.

\section{Materials and Methods}

\subsection{Insects and Rearing Conditions}

The O. furnacalis laboratory colony was originally collected from field corn near the Jiangxi Agricultural University, Nanchang, Jiangxi province, China $\left(28^{\circ} 46^{\prime} 05^{\prime \prime} \mathrm{N}, 115^{\circ} 50^{\prime} 23^{\prime \prime} \mathrm{E}\right)$, and was reared in a growth chamber for more than 10 generations. Insects were kept at $26 \pm 1{ }^{\circ} \mathrm{C}$ with $70 \%$ relative humidity and a 14:10 h (L:D) photoperiod. An artificial diet was used for larval development in the laboratory [34]. Neonate larvae (hatched on the same day) were fed in plastic containers $(15 \mathrm{~cm}$ diameter $\times 10 \mathrm{~cm}$ high) and mature larvae were transferred to boxes with straw paper to pupate. Pupae were sexed based on the morphology of the genital pore and oviposition opening of 
the female and kept separate before eclosion. Male and female moths were maintained separately in $50 \times 50 \times 50 \mathrm{~cm}$ screened cages housed and fed $10 \%$ sucrose water solution, as done previously [35].

\subsection{Chemical and Reagent Doses}

Cadmium chloride $\left(\mathrm{Cd} \mathrm{Cl}_{2}\right)$ was used in this study as the salt of heavy metal $\mathrm{Cd}$. The salt was dissolved in distilled water to make a stock solution (2000 ppm). The stock solution was then diluted and added to the artificial diet to produce a series of artificial diets with different concentrations of $\mathrm{Cd}$. Our previous study tested larval mortality rates in the different $\mathrm{Cd}$ treatments. We found that the larvae mortality rates were $17.5 \%(0.05 \mathrm{mg} / \mathrm{kg}), 20.1 \%(0.5 \mathrm{mg} / \mathrm{kg}), 22.5 \%(5 \mathrm{mg} / \mathrm{kg}), 31.4 \%$ $(10.0 \mathrm{mg} / \mathrm{kg})$, and $52.3 \%(20.0 \mathrm{mg} / \mathrm{kg})$, separately. The baseline Cd content of the artificial diet was $0.031 \pm 0.002 \mathrm{mg} / \mathrm{kg}$. In the control treatment, no Cd was added to the artificial diet and the larval mortality rate was $6.3 \%$ [33]. A previous study has reported that the concentration of $\mathrm{Cd}$ ranges from 0.02 to $0.07 \mathrm{mg} / \mathrm{kg}$ in maize under different treatments [36], whilst it reached sublethal concentrations of $\mathrm{Cd}$ in O. furnacalis. In this study, three $\mathrm{Cd}$ treatments with three different artificial diets with lethal and sublethal concentrations of $\mathrm{Cd}(5,10$, and $20 \mathrm{mg} / \mathrm{kg})$ were selected to test the $\mathrm{Cd}$ accumulations of different life stages. Due to a large number of insects being needed in the other experiments, O. furnacalis individuals were only fed an artificial diet with $5 \mathrm{mg} / \mathrm{kg}$ (sublethal dose) $\mathrm{Cd}$ in the Cd treatment. In this study, only larvae were fed $\mathrm{Cd}$ artificial diets, and there was no $\mathrm{Cd}$ input for pupae and adults.

\subsection{Measurement of $\mathrm{Cd}$ Content}

Thirty 5th instar larvae, two-day-old pupae, and two-day-old adults were randomly collected from different $\mathrm{Cd}$ treatment groups. Each treatment was replicated three to six times. All excretion products were collected from the $5 \mathrm{mg} / \mathrm{kg} \mathrm{Cd}$ treatment groups and the control treatment groups. All 5 th instar larvae samples were starved for $48 \mathrm{~h}$ to decrease the interference of undigested food in the determination of $\mathrm{Cd}$ content. The 5 th instar larvae were transferred to boxes containing rough straw paper for pupation. We then collected larval exuvia, feces, and silk from these boxes where the pupa was kept, and collected pupal cases and wings after eclosion. Because the amounts of these excretion products were very small and were difficult to collect, we collected these in more than 10 different replicates. In $\mathrm{Cd}$ treatment, the control neonate larvae were fed a $\mathrm{Cd}$ artificial diet in each generation. All samples were collected and stored at $-20^{\circ} \mathrm{C}$ and then transferred to plastic petri dishes $(10 \mathrm{~cm}$ in diameter) to oven-dry at $60^{\circ} \mathrm{C}$ for over $36 \mathrm{~h}$, until the body weight remained constant. The dried samples were weighed by an electronic balance to determine the weight of each larva, pupa, and adult sample. Each sample was then grinded into powder. The concentration of $\mathrm{Cd}$ was measured in the Geological Survey of Jiangxi Province, which is an attested institution for measuring the concentration of heavy metals. In total, $0.1-0.5 \mathrm{~g}$ powder samples were dissolved in $65 \% \mathrm{HNO}_{3}$ solution until no solid material remained and the solution was clear. Each treatment was replicated three times. Five different concentrations of $\mathrm{Cd}^{2+}$ standard solutions were prepared for standard curves. The concentration of $\mathrm{Cd}$ in each sample was tested by Inductively Coupled Plasma Mass Spectrometry (ICP-MS) (7700, Agilent Technologies, Santa Clara, CA, USA). The ICP-MS parameters were as follows: RF power was set at $1550 \mathrm{~W}$, plasma gas flow rate was set at $15.0 \mathrm{~L} / \mathrm{min}$, auxiliary gas flow rate was set at $0.9 \mathrm{~L} / \mathrm{min}$, and carrier gas flow rate was set at $1 \mathrm{~L} / \mathrm{min}$ [37]. Cd concentration/individual $(\mu \mathrm{g})=$ concentration $(\mu \mathrm{g} / \mathrm{g})$ * individual dry weight $(\mathrm{g})$.

\subsection{Developmental and Reproductive Evaluation}

Neonate larvae that hatched on the same day were fed in plastic containers (15 cm diameter $\times 10 \mathrm{~cm}$ high) containing either an artificial diet with $\mathrm{Cd}(5 \mathrm{mg} / \mathrm{kg})$ or control diets without $\mathrm{Cd}$ added. Two hundred 3rd instar larvae from these treatments were transferred to different new plastic containers for the observation of larval developmental duration. Fifth instar larvae were transferred to 24-well plates to pupate. All surviving larvae were used in the observation and 
calculation of the pupation rate. All pupae were used in the observation and calculation of pupal weights. Thirty paired adults of $O$. furnacalis were allowed to mate, including five paired adults, in the same transparent plastic bag and six replicates were performed. The number of eggs, and the egg hatchability of those eggs, were recorded in each group bag. During the experiment, the larvae duration, pupae duration, pupation rate, and emergence rate were also recorded. The weights of female and male pupae were measured with an electronic balance. Larvae duration was recorded from the date of larval hatching to the date of pupation. Pupae duration was recorded from the date of pupation to the date of emergence. Pupation rate $=$ (the number of pupae/number of mature larvae $)^{*}$ $100 \%$; emergence rate $=($ the number of adults/number of pupae $) * 100 \%$.

\subsection{Mating Behavior Observation (Wind Tunnel Bioassay)}

The behavioral responses of males were observed in a Plexiglas wind tunnel [38] in a darkened room (L14:D10 photoperiod, $26 \pm 1{ }^{\circ} \mathrm{C}$, relative humidity being $70 \%$ ). The wind tunnel was cylindrical, with a length of $2 \mathrm{~m}$, radius of $0.5 \mathrm{~m}$, and wind speed of $0.3 \mathrm{~m} / \mathrm{s}$. This experiment was performed between 8 and $9 \mathrm{~h}$ after the initiation of scotophase (peak period of female calling).

Mating in $O$. furnacalis is initiated when a sexually mature female extends her pheromone gland in a process known as "calling" and releases a blend of sex pheromones to attract sexually mature males to mate. The male will then respond with a set of standard behaviors that were measurable in our assay. A previous study in our lab found that the calling frequency and calling duration were significantly reduced when females were exposed to Cd via diet [33] (Figure S1). To investigate whether Cd also affects mating behavior in males, we compared the mating responses of $\mathrm{Cd}$-treated males and control males to untreated females.

One-day-old female adults from the control treatment were placed in a $4 \mathrm{~cm}^{2}$ mesh cage as the pheromone source and were placed $20 \mathrm{~cm}$ from the upper air outlet in all tests. The one-day-old males were released individually above the floor of the wind tunnel from a steel screen platform. The males were given $2 \mathrm{~min}$ to respond and the following behavioral categories were recorded: (1) TF: taking flight (male shaking of wings and taking flight); (2) OF: oriented flight (male-oriented flight to the female source); (3) HF: half up-wind flight (male-oriented flight half way to the female source); and (4) SC: source contact (male contact with the female source) [32]. Forty-one paired adults were tested in each treatment and each male and female were tested only once. The response time was from taking flight to source contact or stopping flight (did not contact source within $2 \mathrm{~min}$ ). The times were recorded when males performed these four behavioral categories.

\subsection{Statistical Analysis}

Data were analyzed with SPSS (v24.0). The statistical significance of accumulation in different developmental stages and excretion products was determined by one-way ANOVA. Post hoc analyses were conducted using Tukey's test at alpha $=0.05$ if significant differences were found. The developmental time between $\mathrm{Cd}$ and control treatments was compared using the Mann-Whitney $U$ test (non-normal distributions). The pupal weight, male response time, oviposition, and egg hatchability between $\mathrm{Cd}$ and control treatments were compared using Student's $t$-test with normal distributions. Differences in the pupation rate, eclosion rate, and male behavioral responses were analyzed with a Chi-square test. Normality of the distribution was determined by a Shapiro-Wilk test $(n<50)$ and Kolmogorov-Smirnov test $(n>50)$.

\section{Results}

\subsection{Multiple Routes of Excretion during the Life Cycle Result in Low Levels of Cd Residue in the Adult}

We measured the bioaccumulation of $\mathrm{Cd}$ in the entire life cycle of $\mathrm{O}$. furnacalis, where only larvae were fed on artificial food containing different concentrations of Cd. Larvae fed a 5, 10, and $20 \mathrm{mg} / \mathrm{kg}$ $\mathrm{Cd}$ diet showed the accumulation of $0.60,1.16$, and $2.04 \mu \mathrm{g} \mathrm{Cd}$ per 5th instar larva, respectively, 
and exhibited a dose-dependent response to $\mathrm{Cd}$ accumulation. We also found that larvae mainly accumulate $\mathrm{Cd}$ in the digestive tract $(255.90 \mathrm{mg} / \mathrm{kg})$, while the $\mathrm{Cd}$ concentrations in other tissues were very low (Table S1). Additionally, there was a gradual decrease in the Cd concentration from the larval stage to the pupal stage and the adult stage in all Cd treatments (Figure 1).

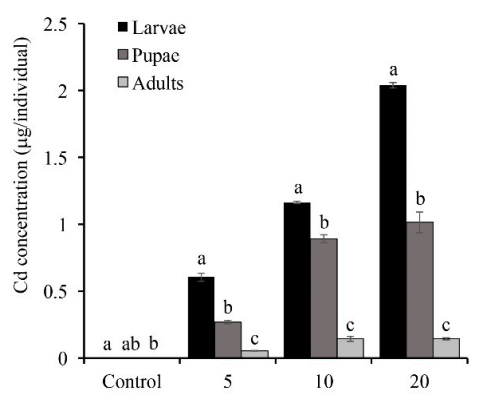

Figure 1. Cadmium (Cd) accumulation in different developmental stages of Ostrinia furnacalis by feeding on artificial food with three concentration of Cd. $5,5 \mathrm{mg} / \mathrm{kg} \mathrm{Cd}$ treatment; $10,10 \mathrm{mg} / \mathrm{kg} \mathrm{Cd}$ treatment; 20, $20 \mathrm{mg} / \mathrm{kg}$ Cd treatment. Cd content was measured by Inductively Coupled Plasma Mass Spectrometry (ICP-MS). Statistical analysis was performed by one-way analysis of variance followed by Tukey's HSD test $(\alpha=0.05)$. Bars and error bars are presented as the mean \pm SE. The different letters in each treatment indicate a significant difference at a $p<0.05$ level. $n=3-6$.

To determine the routes of $\mathrm{Cd}$ excretion in O. furnacalis, we measured the $\mathrm{Cd}$ contents in various excretion products in O. furnacalis fed with Cd (Table S2). We found that high levels of Cd were present in the feces $(95.49 \mathrm{mg} / \mathrm{kg})$, silk $(82.98 \mathrm{mg} / \mathrm{kg})$, pupal cases $(76.87 \mathrm{mg} / \mathrm{kg})$, and larval exuvia $(25.88 \mathrm{mg} / \mathrm{kg})$ in larvae fed with artificial food of $5 \mathrm{mg} / \mathrm{kg} \mathrm{Cd}$.

\subsection{Cd Exposure in the Larval Stage Causes Detrimental Effects on the Development of O. furnacalis}

To determine if $\mathrm{Cd}$ affects the development of $\mathrm{O}$. furnacalis, we compared the developmental timing, pupation rate, eclosion rate, and pupal weight of $O$. furnacalis fed with $C d$ and insects fed with a control diet (Figure 2). The results showed that larvae fed with Cd exhibited a significantly longer developmental time to pupation compared to control larvae $(p<0.001)$ (Figure 2a). Pupae also displayed a significantly longer developmental time to eclosion in the Cd treatment $(p<0.001)$. Cd caused a significant decrease in the pupation rate $\left(\chi^{2}=7.12, p<0.01\right)$ and eclosion rate $\left(\chi^{2}=15.58, p<0.001\right)$ in O.furnacalis (Figure $\left.2 b\right)$. Although the pupal weight was significantly decreased in male pupae under Cd stress $\left(t_{(219)}=5.22, p<0.001\right)$, there was no difference in the female pupal weight between $\mathrm{Cd}$ fed individuals and control individuals $\left(t_{(191)}=0.13, p=0.89\right)$ (Figure 2c).
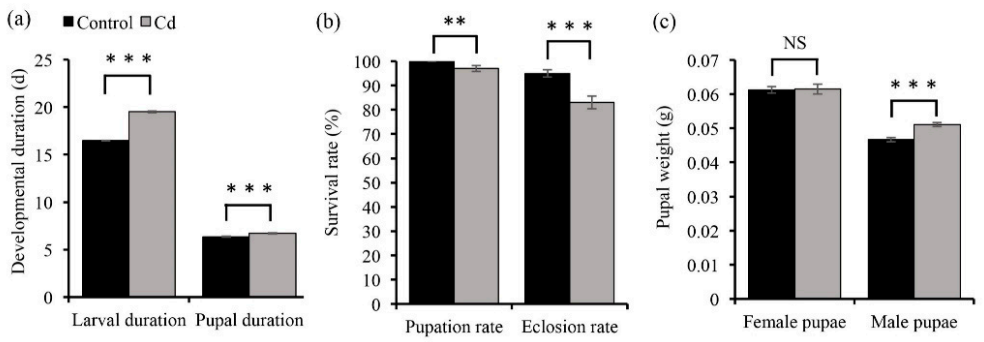

Figure 2. The effects of Cd on the (a) developmental duration, $n$ (larvae) $=210, n$ (pupae) =157-185; (b) survival rate, $n$ (pupation) $=210, n$ (eclosion) $=192-201$; and (c) pupal weight, $n$ (male) = 82-86, $n$ (female) = 106-119, of O. furnacalis. The developmental duration (Mann-Whitney $U$ test), pupal weight (Student's $t$-test), pupation rate (Chi-square test), and eclosion rate (Chi-square test) of $\mathrm{Cd}(5 \mathrm{mg} / \mathrm{kg})$ treatment and control treatment were compared using different tests, according to the normality of distribution. Bars and error bars represent the mean and SE, respectively. NS, no significant effect; ${ }^{* *}, p<0.01$ and ${ }^{* * *}, p<0.001$, compared with the control treatment. 


\subsection{Cd Exposure to Larvae Affects Adult Mating Behavior and Fecundity in O. furnacalis}

To determine whether $\mathrm{Cd}$ affects the mating behavior of $O$. furnacalis (Figure 3a), we compared the mating responses of $\mathrm{Cd}$-treated males and control males to untreated females (Figure 3). The results showed that $\mathrm{Cd}$-treated males displayed lower responses to female calling compared to the control males. Cd-treated males exhibited a reduction in behaviors such as 'taking flight' $\left(\chi^{2}=5.51, p<0.05\right)$, 'oriented flight' $\left(\chi^{2}=5.19, p<0.05\right)$, and ' $1 / 2$ up-wind flight' $\left(\chi^{2}=8.11, p<0.01\right)$, but there were no significant differences in the 'source contact' of female adults compared with control males $\left(\chi^{2}=2.49\right.$, $p=0.12)$. Overall, $\mathrm{Cd}$-treated males displayed significantly more time before contacting females than control males $\left(t_{(48)}=2.31, p<0.05\right)$.

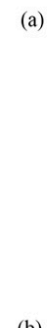

(b)

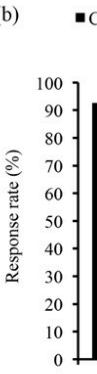

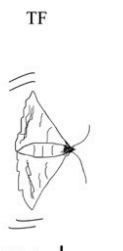

Male

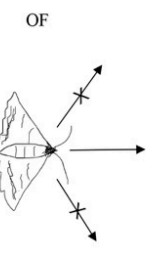

HF
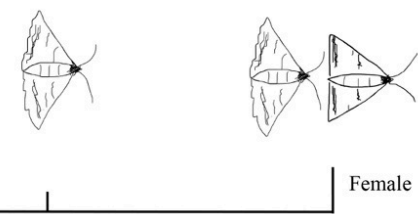

(c)

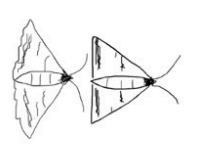$$
\stackrel{+}{\circ}
$$<smiles></smiles>
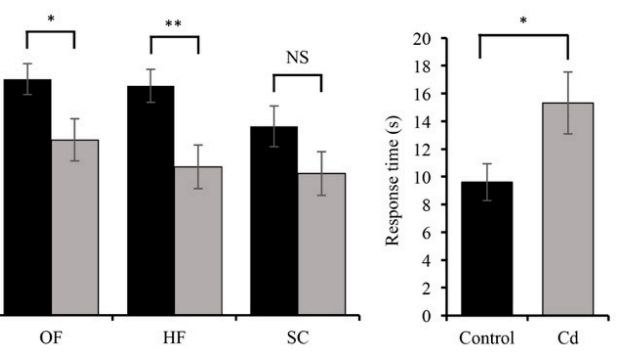

Figure 3. The effects of $\mathrm{Cd}$ stress on the mating behavior of male adults. (a) The mating behavior of male $O$. furnacalis in four stages. The four stages of male response to the female source, including TF, taking flight; $\mathrm{OF}$, oriented flight; $\mathrm{HF}$, half up-wind flight; and SC, source contact. (b) The response rate of males to the female source in these four stages. (c) The response time of males to the female source. The response time is from taking flight to source contact or stopping flight (did not contact source within $2 \mathrm{~min})$. The response rate of males to the female source for $\mathrm{Cd}(5 \mathrm{mg} / \mathrm{kg}$ ) treatment and control treatment was analyzed with a Chi-square test. Three males were non-responders in the control treatment and 11 males were non-responders in the $\mathrm{Cd}$ treatment. The response time of males to the female source for $\mathrm{Cd}$ and control treatments was compared using Student's $t$-test. Bars and error bars represent the mean and SE, respectively. NS: no significant effect; ${ }^{*}, p<0.05$ and ${ }^{* *}, p<0.01$, compared with control treatment. $n=22-41$.

Fecundity in O. furnacalis was also affected by exposure to $\mathrm{Cd}$. There were no differences in the oviposition of $\mathrm{Cd}$ females and control females (Figure 4a), but the egg hatching rate was significantly decreased, regardless of whether either parent or both parents were exposed to Cd (Figure 4b). 
(a)

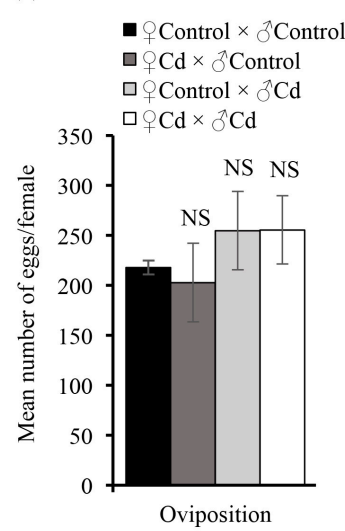

(b)

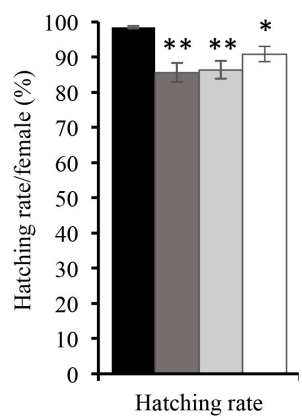

Figure 4. The effects of $\mathrm{Cd}$ on the oviposition (a) and egg hatchability (b) of O. furnacalis. The Cd $(5 \mathrm{mg} / \mathrm{kg})$ treatment and control treatment were compared using Student's $t$-test. Bars and error bars represent the mean and SE, respectively. NS, no significant effect; ${ }^{*}, p<0.05$ and ${ }^{* *}, p<0.01$, compared with control treatment. $n=6$.

\section{Discussion}

A prolonged exposure of $\mathrm{Cd}$ exerts detrimental effects on living organisms due to its high degree of toxicity and rapid adsorption [2,22]. Insects ingest $\mathrm{Cd}$ from Cd-contaminated food and accumulate high concentrations of $\mathrm{Cd}$ in their body $[19,23,39-41]$, which can suppress the growth and development of these insects $[4,20,23,41]$. However, many insect species do not continuously ingest $\mathrm{Cd}$ for their entire life cycle due to metamorphosis and changes in habitats. Such examples include holometabolous insects [24] and migratory insects [26].

In our study, we showed that in a holometabolous herbivore, O. furnacalis, Cd exposure in the larvae could have significant detrimental effects on development and mortality throughout the entire life cycle, even though there is no $\mathrm{Cd}$ intake in the pupal and adult stages. Previous studies have mainly focused on Cd residuals of feces and larval exuvia in the larval stage [39,42], which is the only life stage of host intake in the holometabolous herbivore. In our study, we also found that $O$. furnacalis could excrete high levels of $\mathrm{Cd}$ from silk and pupal cases in the late life stages. This leads to $\mathrm{Cd}$ being gradually excreted during the life cycle and low levels of $\mathrm{Cd}$ remain in the adults. However, these low levels of residual $\mathrm{Cd}$ also resulted in significant detrimental effects on the development and reproduction of adults.

In the present study, the male pupal weight of $O$. furnacalis was significantly higher for $\mathrm{Cd}$ treatment than control treatment, but the female pupal weight displayed no effect under Cd stress. In contrast to our study, Jiang et al. found that female/male pupal weights of Lymantria dispar (Coleoptera: Lymantriidae) were significantly decreased under Cd stress [43]. Similar reduction effects of Cd on body weight were reported in Blaps polycresta (Coleoptera: Tenebrionidae) [44]. The body weight of another insect species, Spodoptera exigua (Lepidoptera: Noctuidae), was not effected by Cd exposure [41]. Therefore, we suggest that the effects of $\mathrm{Cd}$ on pupal weight in insects differ among various species, and the effects vary between female and male individuals. We hypothesize that the different responses of body weight in different insect species may result from the different levels of Cd treatment.

Mating and fecundity are susceptible to toxicants such as insecticides, which can decrease the mating success in two different moth species [32,45]. Similarly, we previously found that Cd can affect mating in $O$. furnacalis by decreasing the calling frequency and calling duration of female adults [33] (Figure S1). In our present study, we showed that $\mathrm{Cd}$ can also affect mating in male $O$. furnacalis by decreasing the activation of male adults in courtship, and extending the response time of males, which may affect the mating success. Our results are similar to those presented in a recent study showing that $\mathrm{Cd}$ prolonged mating latency in another insect species, the vinegar fly Drosophila 
melanogaster (Diptera: Drosophiladae) [21]. This suggests that Cd could affect mating behavior, even in distantly insect species with different mating systems.

$\mathrm{Cd}$ stress did not affect the oviposition in O. furnacalis. However, a decrease of oviposition has been found in many insects exposed to $C d[20,43]$. This suggests that $C d$ exposure has unclear effects on oviposition in insects. In our study, we also found that $\mathrm{Cd}$ exposure for either parent or both parents negatively affected egg hatchability in O. furnacalis, suggesting that gametic damage may occur in both sexes. Other HMs have been shown to affect fecundity by damaging gametes. Sun et al. reported that a high concentration of Ni damaged the quality of sperm bundles, resulting in a decrease of the oviposition and hatching rates in Spodoptera litura (Fabricius) (Lepidoptera: Noctuidae) [46]. Additionally, Osman et al. showed that $\mathrm{Cd}$ exposure caused general necrosis and shape change with distorted chromatin materials in oocytes, which damaged female gonads of the ground beetle, Blaps polycresta (Coleoptera: Tenebrionidae) [44].

Based on our results, we suggest that $C d$ exposure in larvae may result in gametic damage in both male and female adults, and the inhibition of mating behavior and fecundity of adults in O. furnacalis. Previous studies showed that the early formation, growth, and differentiation of egg formation begin in the larval stage [47] and Cd exposure could cause some general intracellular pathologies in insect cells $[48,49]$. We hypothesize that $\mathrm{Cd}$ exposure may cause irreversible damage in larvae cells, and this damage may also persist into adulthood, leading to gametic damage in adults.

\section{Conclusions}

In conclusion, we showed that $\mathrm{Cd}$ exposure during an early life stage has long-lasting detrimental effects on the development of $O$. furnacalis over the entire life cycle and could also result in adverse effects on mating behavior and fecundity, underscoring the urgent need to reduce $\mathrm{Cd}$ pollution in our shared environment.

Supplementary Materials: The following are available online at http://www.mdpi.com/2075-4450/11/1/7/s1: Figure S1: The effects of Cd stress on the (a) calling frequency and (b) calling duration of female O. furnacalis; Table S1: Accumulation of Cd in different tissues and organs of larvae in O. furnacalis from Cd treatment $(5 \mathrm{mg} / \mathrm{kg})$; Table S2: The concentrations of Cd in different products.

Author Contributions: M.L. and H.-Y.W. designed the experiment; M.L., H.-M.C., and Y.-Y.F. performed most of the experiments; M.L., H.C., and H.-Y.W. wrote the manuscript; M.L., X.-C.Z., and J.-X.C. managed insect feeding and sample collection. All authors reviewed the manuscript. All authors have read and agreed to the published version of the manuscript.

Funding: This research is financially supported by the National Natural Science Foundation of China (No. 31760637, 31640064). M.L. is supported by the China Scholarship Council (CSC) (File No. 201708360095). H.C. is supported by the USDA National Institute of Food and Agriculture via Michigan AgBioResearch.

Acknowledgments: We are grateful to Song Wang, Haifeng Yan, Yingying Sun, Yiping Sui, and Qi Ai for assistance in feeding insects and collecting samples. We thank Zinan Wang for data analysis and comments on the manuscript. We also thank Jian Pu and Haosu Cong for comments on the manuscript.

Conflicts of Interest: The authors declare no conflict of interest.

\section{References}

1. Sharma, R.K.; Agrawal, M. Biological effects of heavy metals: An overview. J. Environ. Biol. 2005, 26, 301-313.

2. Tchounwou, P.B.; Yedjou, C.G.; Patlolla, A.K.; Sutton, D.J. Heavy metal toxicity and the environment. EXS 2012, 101, 133-164.

3. Stolpe, C.; Giehren, F.; Krämer, U.; Müller, C. Both heavy metal-amendment of soil and aphid-infestation increase $\mathrm{Cd}$ and $\mathrm{Zn}$ concentrations in phloem exudates of a metal-hyperaccumulating plant. Phytochemistry 2017, 139, 109-117. [CrossRef]

4. Sang, W.; Xu, J.; Bashir, M.H.; Ali, S. Developmental responses of Cryptolaemus montrouzieri to heavy metals transferred across multi-trophic food chain. Chemosphere 2018, 205, 690-697. [CrossRef]

5. Duruibe, J.O.; Ogwuegbu, M.O.C.; Egwurugwu, J.N. Heavy metal pollution and human biotoxic effects. Int. J. Phys. Sci. 2007, 2, 112-118. 
6. Crawford, L.A.; Lepp, N.W.; Hodkinson, I.D. Accumulation and egestion of dietary copper and cadmium by the grasshopper Locusta migratoria R \& F (Orthoptera: Acrididae). Environ. Pollut. 1996, 92, 241-246.

7. Devkota, B.; Schmidt, G. Accumulation of heavy metals in food plants and grasshoppers from the Taigetos Mountains, Greece. Agric. Ecosyst. Environ. 2000, 78, 85-91. [CrossRef]

8. Liu, J.; Liang, J.; Li, K.; Zhang, Z.; Yu, B.; Lu, X.; Yang, J.; Zhu, Q. Correlations between cadmium and mineral nutrients in absorption and accumulation in various genotypes of rice under cadmium stress. Chemosphere 2003, 52, 1467-1473. [CrossRef]

9. Thompson, J.; Bannigan, J. Cadmium: Toxic effects on the reproductive system and the embryo. Reprod. Toxicol. 2008, 25, 304-315. [CrossRef]

10. Borowiak, K.; Kanclerz, J.; Mleczek, M.; Lisiak, M.; Drzewiecka, K. Accumulation of Cd and Pb in water, sediment and two littoral plants (Phragmites australis, Typha angustifolia) of freshwater ecosystem. Arch. Environ. Prot. 2016, 42, 47-57. [CrossRef]

11. Chen, W.; Lu, S.; Peng, C.; Jiao, W.; Wang, M. Accumulation of Cd in agricultural soil under long-term reclaimed water irrigation. Environ. Pollut. 2013, 178, 294-299. [CrossRef]

12. Li, Z.; Ma, Z.; van der Kuijp, T.J.; Yuan, Z.; Huang, L. A review of soil heavy metal pollution from mines in China: Pollution and health risk assessment. Sci. Total Environ. 2014, 468, 843-853. [CrossRef]

13. Li, H.; Luo, N.; Li, Y.W.; Cai, Q.Y.; Li, H.Y.; Mo, C.H.; Wong, M.H. Cadmium in rice: Transport mechanisms, influencing factors, and minimizing measures. Environ. Pollut. 2017, 224, 622-630. [CrossRef]

14. Wang, M.; Chen, W.; Peng, C. Risk assessment of Cd polluted paddy soils in the industrial and township areas in Hunan, Southern China. Chemosphere 2016, 144, 346-351. [CrossRef]

15. Van Nguyen, N.; Ferrero, A. Meeting the Challenges of Global Rice Production; Springer: New York, NY, USA, 2006.

16. Inaba, T.; Kobayashi, E.; Suwazono, Y.; Uetani, M.; Oishi, M.; Nakagawa, H.; Nogawa, K. Estimation of cumulative cadmium intake causing Itai-itai disease. Toxicol. Lett. 2005, 159, 192-201. [CrossRef]

17. Wang, X.; Zhang, C.; Qiu, B.; Ashraf, U.; Azad, R.; Wu, J.; Ali, S. Biotransfer of Cd along a soil-plant-mealybug-ladybird food chain: A comparison with host plants. Chemosphere 2017, 168, 699-706. [CrossRef]

18. Zhuang, P.; Zou, H.; Shu, W. Biotransfer of heavy metals along a soil-plant-insect-chicken food chain: Field study. J. Environ. Sci. 2009, 21, 849-853. [CrossRef]

19. Zhang, Y.; Sun, G.; Yang, M.; Wu, H.; Zhang, J.; Song, S.; Ma, E.; Guo, Y. Chronic accumulation of cadmium and its effects on antioxidant enzymes and malondialdehyde in Oxya chinensis (Orthoptera: Acridoidea). Ecotoxicol. Environ. Saf. 2011, 74, 1355-1362. [CrossRef]

20. Cervera, A.; Maymó, A.C.; Sendra, M.; Martínezpardo, R.; Garcerá, M.D. Cadmium effects on development and reproduction of Oncopeltus fasciatus (Heteroptera: Lygaeidae). J. Insect Physiol. 2004, 50, 737-749. [CrossRef]

21. Hu, X.; Fu, W.; Yang, X.; Mu, Y.; Gu, W.; Zhang, M. Effects of cadmium on fecundity and defence ability of Drosophila melanogaster. Ecotoxicol. Environ. Saf. 2019, 171, 871-877. [CrossRef]

22. Plachetka-Bozek, A.; Kafel, A.; Augustyniak, M. Reproduction and development of Spodoptera exigua from cadmium and control strains under differentiated cadmium stress. Ecotoxicol. Environ. Saf. 2018, 166, 138-145. [CrossRef] [PubMed]

23. Li, K.; Chen, J.; Jin, P.; Li, J.; Wang, J.; Shu, Y. Effects of Cd accumulation on cutworm Spodoptera litura larvae via $\mathrm{Cd}$ treated Chinese flowering cabbage Brassica campestris and artificial diets. Chemosphere 2018, 200, 151-163. [CrossRef] [PubMed]

24. Rivero, A.; Giron, D.; Casas, J. Lifetime allocation of juvenile and adult nutritional resources to egg production in a holometabolous insect. Proc. R. Soc. B Biol. Sci. 2001, 268, 1231-1237. [CrossRef] [PubMed]

25. Balduf, W. The rise of entomophagy among Lepidoptera. Am. Nat. 1938, 72, 358-379. [CrossRef]

26. Holland, R.A.; Wikelski, M.; Wilcove, D.S. How and why do insects migrate? Science 2006, 313, 794-796. [CrossRef]

27. Wang, Z.; Lu, X.; He, K.; Zhou, D. Review of history, present situation and prospect of the Asian maize borer research in China. J. Shenyang Agric. Univ. Chin. J. 2000, 31, 402-412.

28. Afidchao, M.M.; Cjm, M.; De, S.G.R. Asian corn borer (ACB) and non-ACB pests in GM corn (Zea mays L.) in the Philippines. Pest Manag. Sci. 2013, 69, 792-801. [CrossRef] 
29. Wang, S.; Wu, W.; Liu, F.; Liao, R.; Hu, Y. Accumulation of heavy metals in soil-crop systems: A review for wheat and corn. Environ. Sci. Pollut. Res. Int. 2017, 24, 15209-15225. [CrossRef]

30. Cui, J.; Wang, W.; Peng, Y.; Zhou, F.; He, D.; Wang, J.; Chang, Y.; Yang, J.; Zhou, J.; Wang, W.; et al. Effects of simulated Cd deposition on soil Cd availability, microbial response, and crop Cd uptake in the passivation-remediation process of Cd-contaminated purple soil. Sci. Total Environ. 2019, 683, 782-792. [CrossRef]

31. Roelofs, W.L.; Rooney, A.P. Molecular genetics and evolution of pheromone biosynthesis in Lepidoptera. Proc. Natl. Acad. Sci. USA 2003, 100, 9179-9184. [CrossRef]

32. Wei, H.Y.; Du, J.W. Sublethal effects of larval treatment with deltamethrin on moth sex pheromone communication system of the Asian corn borer. Ostrinia furnacalis. Pestic. Biochem. Physiol. 2004, 80, 12-20. [CrossRef]

33. Cao, H.; Wei, H. Effect of the heavy metals $\mathrm{Cd}^{2+}$ and $\mathrm{Ni}^{2+}$ on the calling behavior of Ostrinia furnacalis (Lepidoptera: Crambidae). Chin. J. Appl. Entomol. 2016, 53, 793-801.

34. Zhou, D.R.; Wang, Y.Y.; Liu, B.L.; Ju, Z.L. Study on large breeding of Ostrinia furnacalis I: An artificial diet and its improvement. Acta Pharm. Sin. 1980, 7, 113-122.

35. Luo, M.; Zhou, X.C.; Wang, Z.; Chen, J.X.; Chung, H.; Wei, H.Y. Identification and Gene Expression Analysis of the Pheromone Biosynthesis Activating Neuropeptide Receptor (PBANR) From the Ostrinia furnacalis (Lepidoptera: Pyralidae). J. Insect Sci. 2019, 19, 25. [CrossRef]

36. Lavado, R.S.; Rodríguez, M.; Alvarez, R.; Taboada, M.A.; Zubillaga, M.S. Transfer of potentially toxic elements from biosolid-treated soils to maize and wheat crops. Agric. Ecosyst. Environ. 2007, 118, 312-318. [CrossRef]

37. Zarco-Fernandez, S.; Coto-García, A.; Munoz-Olivas, R.; Sanz-Landaluze, J.; Rainieri, S.; Cámara, C. Bioconcentration of ionic cadmium and cadmium selenide quantum dots in zebrafish larvae. Chemosphere 2016, 148, 328-335. [CrossRef]

38. Baker, T.; Linn, C. Wind tunnels in pheromone research. In Techniques in Pheromone Research; Springer: New York, NY, USA, 1984; pp. 75-110.

39. Ding, P.; Zhuang, P.; Li, Z.; Xia, H.; Lu, H. Accumulation and detoxification of cadmium by larvae of Prodenia litura (Lepidoptera: Noctuidae) feeding on Cd-enriched amaranth leaves. Chemosphere 2013, 91, 28-34. [CrossRef]

40. Gao, Q.; Wang, X.; Wang, W.; Lei, C.; Zhu, F. Influences of chromium and cadmium on the development of black soldier fly larvae. Environ. Sci. Pollut. Res. 2017, 24, 8637-8644. [CrossRef]

41. Kafel, A.; Zawisza-Raszka, A.; Szulińska, E. Effects of multigenerational cadmium exposure of insects (Spodoptera exigua larvae) on anti-oxidant response in haemolymph and developmental parameters. Environ. Pollut. 2012, 162, 8-14. [CrossRef]

42. Bagatto, G.; Shorthouse, J.D. Accumulation of $\mathrm{Cu}$ and $\mathrm{Ni}$ in successive stages of Lymantria dispar L. (Lymantriidae, Lepidoptera) near ore smelters at Sudbury, Ontario, Canada. Environ. Pollut. 1996, 92, 7-12. [CrossRef]

43. Jiang, D.; Yan, S. Effects of Cd, Zn or Pb stress in Populus alba berolinensis on the development and reproduction of Lymantria dispar. Ecotoxicology 2017, 26, 1305-1313. [CrossRef] [PubMed]

44. Osman, W.; El-Samad, L.M.; Mokhamer, E.H.; El-Touhamy, A.; Shonouda, M. Ecological, morphological, and histological studies on Blaps polycresta (Coleoptera: Tenebrionidae) as biomonitors of cadmium soil pollution. Environ. Sci. Pollut. Res. 2015, 22, 14104-14115. [CrossRef] [PubMed]

45. Wei, H.; Huang, Y.; Du, J. Sex pheromones and reproductive behavior of Spodoptera litura (Fabricius) moths reared from larvae treated with four insecticides. J. Chem. Ecol. 2004, 30, 1457-1466. [CrossRef] [PubMed]

46. Sun, H.; Wu, W.; Guo, J.; Xiao, R.; Jiang, F.; Zheng, L.; Zhang, G. Effects of nickel exposure on testicular function, oxidative stress, and male reproductive dysfunction in Spodoptera litura Fabricius. Chemosphere 2016, 148, 178-187. [CrossRef] [PubMed]

47. Telfer, W.H. Egg formation in Lepidoptera. J. Insect Sci. 2009, 9, 1-21. [CrossRef] 
48. Braeckman, B.P. Heavy Metal Toxicity in an Insect Cell Line (Methyl- $\mathrm{HgCl}, \mathrm{HgCl}_{2}, \mathrm{CdCl}_{2}$ and $\mathrm{CuSO}_{4}$ ). In Cellular Effects of Heavy Metals; Springer: New York, NY, USA, 2011; pp. 115-144.

49. Braeckman, B.; Raes, H.; Van Hoye, D. Heavy-metal toxicity in an insect cell line. Effects of cadmium chloride, mercuric chloride and methylmercuric chloride on cell viability and proliferation in Aedes albopictus cells. Cell Biol. Toxicol. 1997, 13, 389-397. [CrossRef]

(C) 2019 by the authors. Licensee MDPI, Basel, Switzerland. This article is an open access article distributed under the terms and conditions of the Creative Commons Attribution (CC BY) license (http://creativecommons.org/licenses/by/4.0/). 